\title{
New Approaches to Quantifying Tensile Strength Variability and Size Effects in Unidirectional Composites
}

\author{
Michael R. Wisnom ${ }^{1}$, M. Asun Cantera ${ }^{2}$, Gergely Czél ${ }^{3,1}$ and Meisam Jalalvand ${ }^{1}$ \\ ${ }^{1}$ Bristol Composites Institute (ACCIS), University of Bristol, UK \\ ${ }^{2}$ Materials+Tecnologies/Mechanics of Materials, Department of Mechanical Engineering, \\ University of the Basque Country, UPV/EHU, Spain \\ ${ }^{3}$ Department of Polymer Engineering, Budapest University of Technology and Economics, \\ Hungary
}

\begin{abstract}
Two methods were used to investigate the variability of tensile failure strain of unidirectional high strength carbon/epoxy. Scaled tests on glass/carbon hybrid specimens showed a significant size effect and reduction of failure strain with stressed volume consistent with a Weibull modulus of 25. Ply fragmentation tests were also carried out, producing multiple carbon fractures in a single specimen. Strains from these tests also fitted a Weibull distribution, and gave a similar Weibull modulus to the scaled tests.
\end{abstract}

\section{INTRODUCTION}

Composites exhibit a size effect with the tensile strength decreasing with stressed volume [1]. This is caused by material variability and the associated distribution of defects. Quantifying variability and size effects is difficult because tensile test specimens tend to fail at the grips due to stress concentrations. This causes a systematic decrease of the failure strain and creates additional test variability which can mask the underlying trends in strength. Laborious and time consuming approaches to minimise stress concentrations such as very gradual tapering of specimens are required to achieve consistent gauge section failures and enable good data to be obtained on size effects [2].

Recent tests with glass/carbon hybrid specimens have demonstrated that the stress concentration in the carbon can be completely eliminated by sandwiching it between glass plies. Failures occur in the gauge section followed by immediate

\footnotetext{
${ }^{1}$ Michael R. Wisnom and Meisam Jalalvand, Bristol Composites Institute (ACCIS), University of Bristol, UK

${ }^{2}$ M. Asun Cantera, Materials+Tecnologies/Mechanics of Materials, Department of Mechanical Engineering, University of the Basque Country, UPV/EHU, Spain

${ }^{3}$ Gergely Czél, Department of Polymer Engineering, Budapest University of Technology and Economics, Hungary
} 
delamination [3]. In this paper, the new hybrid test method is applied to scaled specimens in order to determine the magnitude of the size effect.

When the carbon layers in hybrid specimens are thin enough so that the mode II energy release rate is lower than the fracture toughness of the interface, there is no catastrophic delamination after fibre fracture, and multiple fragmentations occur, associated with a plateau on the stress-strain curve [4]. Using such tests to deduce the strength variability and Weibull modulus from the strains at the fragmentation events along the plateau is also explored.

\section{HYBRID TEST METHOD}

Finite element analysis of carbon fibre plies sandwiched between layers of glass has shown that the stress concentration at the grips is completely eliminated. Fig. 1 shows the strain distribution in the loading direction in a quarter finite element model [3]. Whilst there is a very high strain at the tip of the tab in the glass layer, the strains in the carbon are actually lower than the average far-field strain because from equilibrium considerations the total load across the thickness has to be constant along the length. Therefore if the stresses are higher in the glass, they must be lower in the carbon. The strain distribution through the thickness of the specimen at the tab tip is shown in Fig. 2. As a result of the lower strain at the tab, it was found that consistent gauge section failures could be obtained. After carbon failure, delamination occurs, giving a clear load drop at which point the strain at failure can be measured with an extensometer or strain gauge. There are thermal residual strains due to the different expansion coefficients of the glass and carbon plies if these are cured together at elevated temperature, but the magnitudes are small, and they can be subtracted in order to obtain the true mechanical strain at failure. A further advantage is that it is not necessary to use additional bonded-on tabs as the surface glass layers effectively act as in-situ tabs, protecting the carbon from the grips of the test machine.

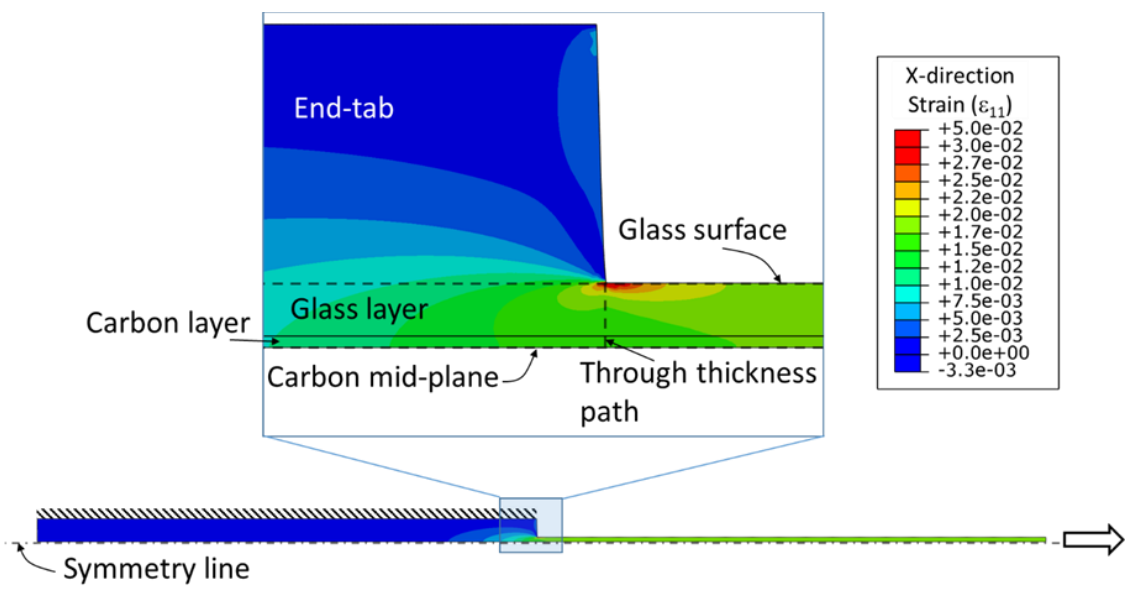

Figure. 1. Strains in loading direction in glass/carbon hybrid test specimen [3] 


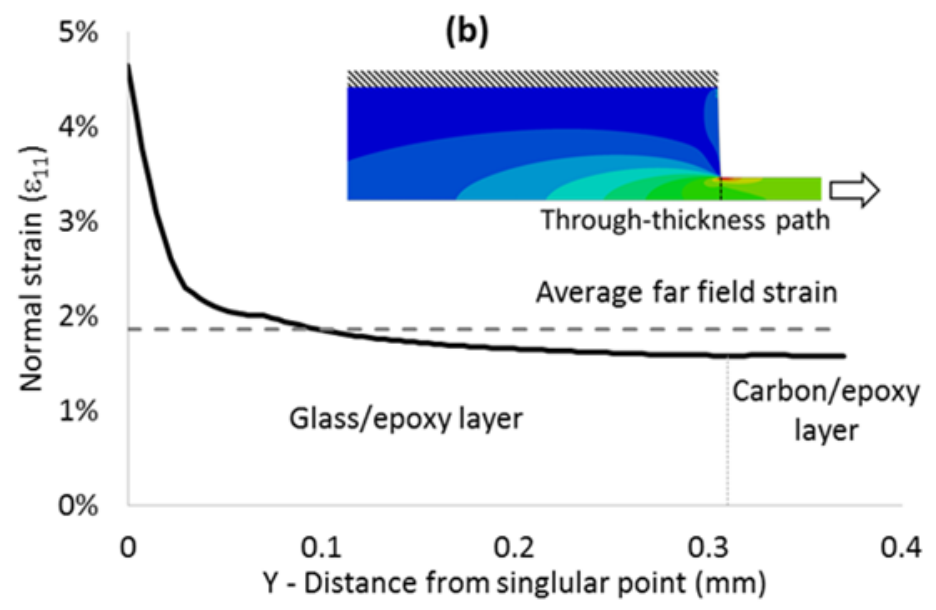

Figure 2. Strain distribution through the half thickness of hybrid specimen [3]

\section{SCALED TENSION TESTS}

Hybrid specimens were made from thin TC35/K50 carbon/epoxy prepreg from SK Chemicals between standard thickness Hexcel S2-glass/913 epoxy. The cured ply thicknesses were $0.024 \mathrm{~mm}$ and $0.155 \mathrm{~mm}$ respectively. Baseline specimens were made with layup $\left[\mathrm{SG}_{2} / \mathrm{TC}_{2} 5_{2}\right]_{\mathrm{S}}$ with a width of $5 \mathrm{~mm}$ and gauge length of 30 $\mathrm{mm}$. Three further sets of specimens were made with all dimensions scaled up by factors of 2, 4 and 8 in each direction. The largest specimens therefore had a layup of $\left[\mathrm{SG}_{16} / \mathrm{TC} 35_{16}\right] \mathrm{s}$ with width $40 \mathrm{~mm}$ and gauge length $240 \mathrm{~mm}$.

Tests were carried out in tension in a servo-hydraulic test machine with no end tabs and scaled cross-head displacement rates from $1 \mathrm{~mm} / \mathrm{min}$ for the smallest to 8 $\mathrm{mm} / \mathrm{min}$ for the largest specimens. The carbon layer in the majority of the specimens failed in the gauge section which means that the stress-concentrations around the grips were successfully eliminated. Strains were measured using an Imetrum videogauge system. Results are shown in Table 1, which include a correction for the residual thermal strains in the carbon of $-0.0247 \%$, the same for all specimens since the layups are scaled. 
TABLE 1. SCALED TENSILE TEST RESULTS CORRECTED FOR THERMAL STRAINS

\begin{tabular}{|ccc|}
\hline Lay-up & $\begin{array}{c}\text { No. of } \\
\text { specimens }\end{array}$ & $\begin{array}{c}\text { Carbon layer } \\
\text { failure strain [\%] } \\
\text { (CV rel.\%) }\end{array}$ \\
\hline$\left[\mathrm{SG}_{2} / \mathrm{TC} 35_{2}\right]_{\mathrm{s}}$ & 9 & $2.028(3.6)$ \\
\hline$\left[\mathrm{SG}_{4} / \mathrm{TC} 35_{4}\right]_{\mathrm{s}}$ & 10 & $1.854(4.9)$ \\
\hline$\left[\mathrm{SG}_{8} / \mathrm{TC} 35_{8}\right]_{\mathrm{s}}$ & 9 & $1.784(2.6)$ \\
\hline$\left[\mathrm{SG}_{16} / \mathrm{TC} 35_{16}\right]_{\mathrm{s}}$ & 6 & $1.560(5.5)$ \\
\hline
\end{tabular}

There is a strong size effect, with a decrease in strain at failure of $23 \%$ over the factor of 8 scaling of linear dimensions. These results are plotted in Fig. 3 on a loglog scale against the volume of carbon in the gauge section. A best fit straight line goes through the error bars of all of the test data. A Weibull modulus of 25 was obtained from the slope, which is comparable to other reported values for unidirectional carbon/epoxy, which are typically in the range from 13 to 41 [1].

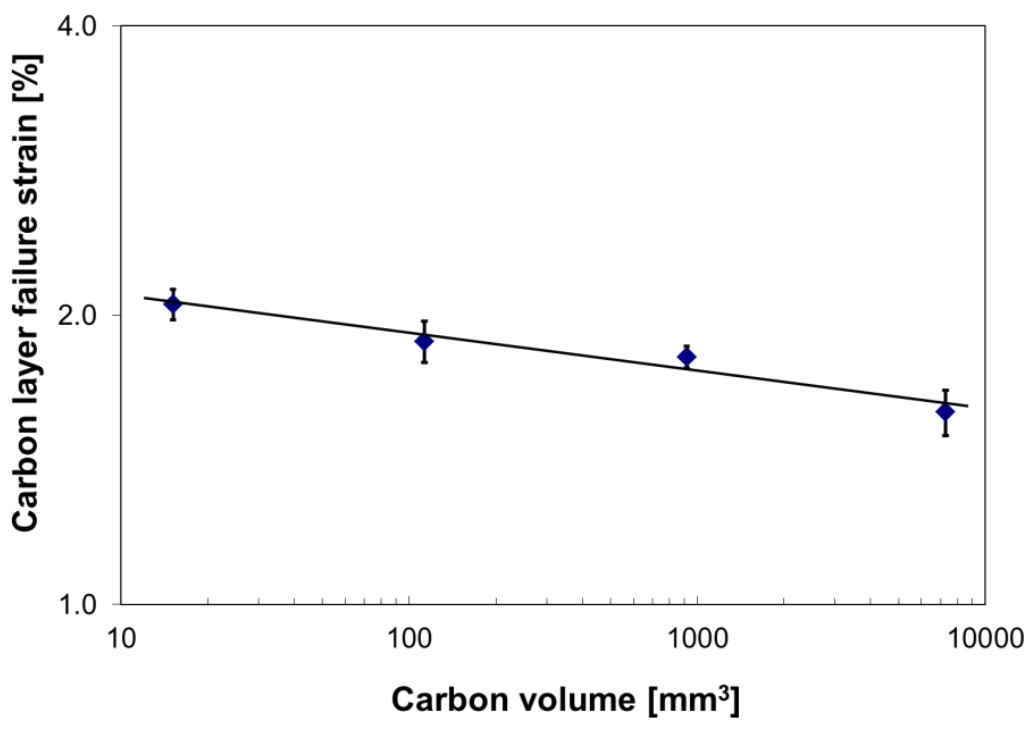

Figure 3. Weibull fit to failure strains from scaled tensile tests 


\section{PLY FRAGMENTATION TESTS}

In the scaled tests delamination occurred immediately after the first carbon fracture. However in previous tests using thinner carbon plies, it has been shown that delamination can be suppressed due to insufficient energy release rate to drive it [4]. This results in a plateau on the stress-strain curve (Fig. 4) with a small slope as progressively stronger parts of the carbon ply fragment. This behaviour is analogous to a single fibre fragmentation test, but at the ply rather than single fibre level.

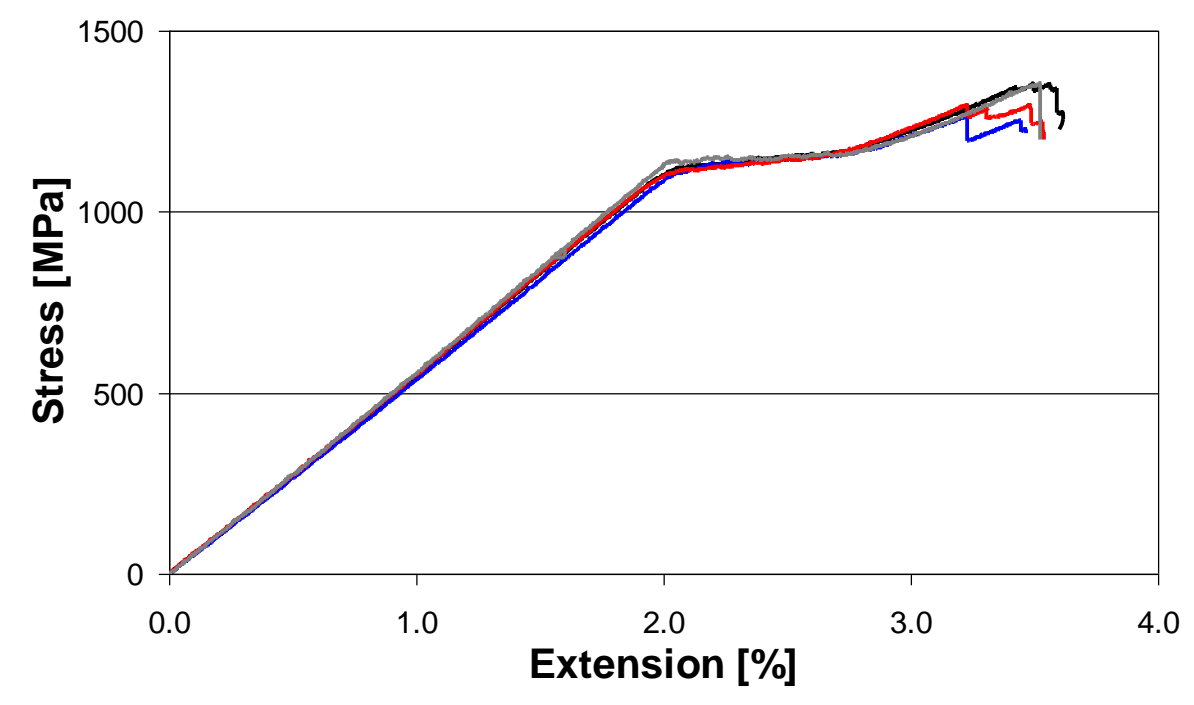

Figure 4: Typical tensile response of thin-ply glass/carbon/glass hybrid specimen [5]

A single specimen therefore produces multiple fractures that can be used as the basis for establishing the composite Weibull modulus. To do this, it is necessary to prevent delamination occurring. Previously this was done by using thinner plies. However, it has been demonstrated that there is a hybrid effect, with thinner plies showing an increased strain at failure due to inhibiting the formation of critical clusters of fibre breaks [6]. The effect is quite significant, with an increase of up to $20 \%$ in strain at failure reported for a layer thickness of only $0.029 \mathrm{~mm}$. Both experimental and modelling results indicated that the effect was only present for ply thicknesses below $0.09 \mathrm{~mm}$ [6]. A carbon thickness of about $0.1 \mathrm{~mm}$ was therefore used for the smallest scaled tests presented earlier, in order to avoid potential hybrid effects and ensure that any differences in failure strain were only due to the difference in stressed volume.

To obtain fragmentation whilst maintaining the same ply thickness an alternative method was used to suppress delamination by increasing the fracture toughness of the carbon/glass interface. Plates were manufactured with the same layup as the smallest scaled tests, but with additional layers of Hexcel 913 resin film (RF) of $34 \mathrm{~g} / \mathrm{m}^{2}$ areal density on either side of the carbon plies. Test sections 
$200 \mathrm{~mm}$ long were used to allow for plenty of fragmentation events in a single specimen, and the width was increased to $20 \mathrm{~mm}$.

Fig. 5 shows a typical specimen at the end of the test, which has a large number of fragmentations, mostly going across the full width. Each carbon fracture is accompanied by a small amount of local delamination, which turns the specimen from black to yellow, the colour of the glass/epoxy, making the fragmentations easy to observe visually. Strains were measured by a video extensometer and the values at the different fracture events were determined afterwards by replaying the video slowly. After fragmentation occurs, the strain in the carbon is no longer the same as the measured overall average strain. The load transferred from the broken carbon fragments gives a local increase in strain in the glass adjacent to the fragments, which results in a higher overall measured strain than that in the carbon. This can be corrected for by a simple shear lag analysis [7]. As an alternative to visual identification of fractures, it is also possible to determine the fragmentation events from acoustic emission, and it has previously been demonstrated that with appropriate choice of filtering parameters there is a one to one correlation between fragmentation and acoustic events [8].

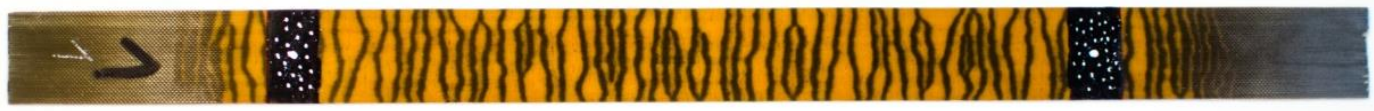

Figure 5. Typical $\left[\mathrm{SG}_{2} / \mathrm{RF} / \mathrm{TC} 35_{2}\right]_{\mathrm{S}}$ specimen after ply fragmentation

As fragmentation progresses, the volume of stressed material decreases, as there is a lower stressed portion at the ends of each fragment. It is necessary to correct for this effect in order to avoid bias due to the successive fragmentation strains being for different volumes. This can be done using shear lag theory, assuming the strain in the carbon varies linearly from zero up to the equilibrium value along the length of each fragment. For the purposes of this calculation, the fragments were assumed to be of equal length.

The strain distribution can then be integrated along the length to calculate an equivalent strain accounting for the number of fragments and associated variation of strain. This equivalent constant strain has the same probability of failure as the actual varying strain distribution over the whole ply. However the correction requires a value of the Weibull modulus, which is initially unknown, and so an iterative procedure is necessary.

Various different ways of performing the calculations have been investigated and some preliminary results are shown in Fig. 6. All the failure strains obtained from a series of 8 specimens with an average of about 50 fragmentations each were represented on Weibull plots. Fig. 6 shows typical results for one of the specimens with 54 fragmentations. The fit to the Weibull model is good, with most of the points lying within the $95 \%$ confidence intervals. The Weibull modulus obtained from the slope of this graph is 24.6 , which is similar to that obtained from the scaled tensile tests. 


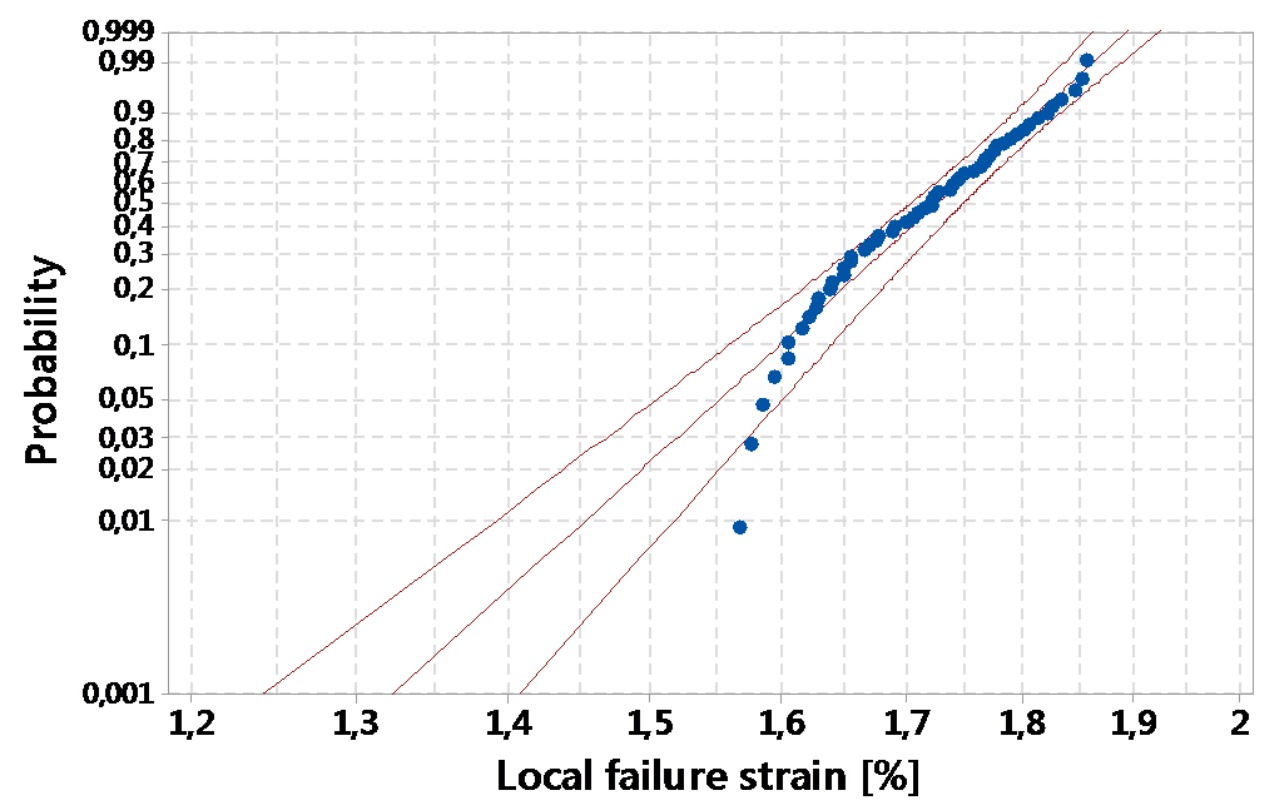

Figure 6. Typical Weibull plot for fragmentation strains from one specimen

\section{CONCLUSIONS}

Hybrid glass/carbon specimens were used to establish failure strains for TC35 carbon/epoxy. Stress concentrations at the grips were successfully eliminated, and most specimens failed in the gauge section. Scaled specimens where all dimensions were simultaneously increased by factors of 2, 4 and 8 showed a reduction in strain to failure with increasing stressed volume. The largest specimens had a strain $23 \%$ lower than the smallest. Plots of strain against volume on a log-log scale showed a good fit to a Weibull model, with a Weibull modulus of about 25 .

Specimens with resin film added to the glass/carbon interfaces to supress delamination after fibre failure produced progressive ply fragmentation. Strains at failure deduced from multiple fragmentation events on multiple specimens fitted a Weibull distribution well, with a Weibull modulus similar to that determined from the scaled tests. This looks promising as an alternative method for deducing the Weibull modulus for tensile failure of composites.

\section{ACKNOWLEDGEMENTS}

This work was partly funded under the UK Engineering and Physical Sciences Research Council Programme Grant EP/I02946X/1 on High Performance Ductile Composite Technology in collaboration with Imperial College London. Gergely Czél acknowledges the Hungarian Academy of Sciences for funding through the János Bolyai scholarship and the Hungarian National Research, Development and Innovation Office - NKFIH for funding through grants ref. OTKA K 116070 and OTKA PD 121121. M. Asun Cantera acknowledges the Spanish Government for 
funding the research stay at the University of Bristol through the program Castillejo JC 2015-00148.

\section{REFERENCES}

1. Wisnom MR. Size effects in the testing of fibre-composite materials. Composites Science and Technology. 1999, 59, 1937-1957.

2. Wisnom MR, Khan B, Hallett SR. Size effects in unnotched tensile strength of unidirectional and quasi-isotropic carbon/epoxy composites. Composite Structures. 2008, 84, 21-28.

3. Czel G, Jalalvand M, Wisnom MR. Hybrid specimens eliminating stress concentrations in tensile and compressive testing of unidirectional composites. Composites: Part A. 2016, 91, 436-447.

4. Czel G, Wisnom MR. Demonstration of pseudo-ductility in high performance glass/epoxy composites by hybridisation with thin-ply carbon prepreg. Composites Part A 2013; 52:23-30.

5. Czel G, Jalalvand M, Wisnom MR. Design and characterization of advanced pseudo-ductile unidirectional thin-ply carbon/epoxy-glass/ epoxy hybrid composites, Composite Structures. 2016, 143, 362-370.

6. Wisnom MR, Czel G, Swolfs Y, Jalalvand M, Gorbatikh L, Verpoest I. Hybrid effects in thin ply carbon/glass unidirectional laminates: accurate experimental determination and prediction. Composites Part A: Applied Science and Manufacturing. 2016, 88, 131-139.

7. Jalalvand M, Czél G, Wisnom MR. Damage analysis of pseudo-ductile thin-ply UD hybrid composites - A new analytical method. Composites: Part A: Applied Science and Manufacturing. 2014: 69, 83-93.

8. Fotouhi M, Suwarta P, Jalalvand M, Czel G, Wisnom MR. Detection of fibre fracture and ply fragmentation in thin-ply UD carbon/glass hybrid laminates using acoustic emission. Composites Part A: Applied Science and Manufacturing. 2016, 86, 66-76. 